\title{
Missed opportunities in family planning: process evaluation of family planning program in Omo Nada district, Oromia region, Ethiopia
}

Misganu Endriyas ${ }^{1 *}$, Tefera Belachew ${ }^{3}$ and Berhane Megerssa ${ }^{2}$

\begin{abstract}
Background: Family planning (FP) program is a key program to avert unbalanced human population growth, maternal mortality, unintended pregnancy, unsafe abortion, sexually transmitted diseases and malnutrition. To address these aims, all services that clients receive must be of consistently high quality. So, services that clients receive should be monitored and evaluated.

Methods: Case study was carried out in January, 2011, in Omo Nada district, Oromia region. Data were collected using different data collection methods. Process of FP program was evaluated using Judith Bruce model. Geographical accessibility, availability of resources for service provision and technical compliance were assessed. Level of program implementation was measured using stakeholders' agreed indicators and judgment matrix.

Results: Though overall program implementation level was good and clients were satisfied, notable gaps observed were absence of crucial materials, poor provision of information in relation to method given, poor technical performance in following aseptic procedure, and poor integration of services.

Conclusion: Service provision should be monitored to maintain quality of service by integrating available services in resource limited setting.
\end{abstract}

Keywords: Process evaluation, Family planning, Service quality, Missed opportunities, Omo Nada, Oromia, Ethiopia

\section{Background}

Family planning (FP) is a key intervention for improving the health of women, men and children $[1,2]$. Contraceptives prevent unintended pregnancies, reduce number of abortions, and lower incidence of death and disability related to complications of pregnancy and childbirth [3]. As an important component of reproductive health $(\mathrm{RH})$, quality FP is recognized as a human right. All individuals have right to access, choice, and benefits of scientific progress in the selection of FP methods [4].

Despite decades of international agreements declaring the need for urgent action to improve wellbeing among

\footnotetext{
*Correspondence: misganuendrias@yahoo.com

${ }^{1}$ Health Research and Technology Transfer Support Process, SNNPR Health

Bureau, Hawassa, Ethiopia

Full list of author information is available at the end of the article
}

women and newborns, deaths and poor health among these groups have remained high in developing world [5]. In developing countries, more than 120 million couples have an unmet need for safe and effective contraception. Out of 182 million pregnancies occurring each year in the developing world, about $40 \%$ are unwanted or ill-timed [6]. In 2008, an estimated $41 \%$ of all pregnancies in Ethiopia were unintended; $48 \%$ of all pregnancies in Oromia region were unintended and $76 \%$ of reproductive age of this region had unmet need to modern contraceptives [7].

Ethiopian ministry of health, with respect to improving maternal and child health, had planned to increase contraceptive prevalence rate to $66 \%$ by 2015 . In order to achieve this target, the ministry had given priority to the provision of safe motherhood services such as family planning in the community [8]. But according to

(c) The Author(s). 2018 Open Access This article is distributed under the terms of the Creative Commons Attribution 4.0 International License (http://creativecommons.org/licenses/by/4.0/), which permits unrestricted use, distribution, and 
Ethiopian Demographic and Health Survey (2011), modern contraceptive prevalence rate was 27.3 nationally and 24.9 in the study region which was below national average [9].

The outcome of women health in developing countries is very low due to different socio-economic, socio-cultural factors, and lack of healthcare services. More specifically, restrictions on information about sexuality and contraception limit people's ability to make choices regarding their own sexual and RH and rights [10].

For FP to meet its goals, all services that clients receive must be of consistently high quality and services that clients receive should be monitored and evaluated. Successful delivery of FP services requires proper coordination of activities that are involved at the various steps of the service delivery chain: counseling, provision of a wide choice of contraceptives, follow-up and appropriate referral, supervision, monitoring and evaluation, and a functional logistics system [11]. The purpose of this evaluation was to assess the program operations to highlight gaps to improve program implementation.

\section{Methods}

Facility based descriptive case study was conducted in Omo Nada district in January, 2011. Case study was used because it lets to focus on selected area, in-depth understanding of issue and collecting data in different ways $[12,13]$. Omo Nada district is one of rural districts in Oromia region, Ethiopia. In 2011, the district had four health centers. We considered two health centers (HCs) (Asendabo and Nada) purposely as the rest two were relatively new.

Building on work of Avedis Donabedian [14], Judith Bruce developed a frameworks for assessing quality of FP services [15]. We used Bruce's framework as it provides a comprehensive framework for evaluating interpersonal dimension of quality of care and for developing appropriate indicators. The Bruce framework consists of six main elements: choice of methods, information to clients, technical competence, interpersonal relations (the degree of empathy; trust and confidentiality), mechanisms for encouraging continuity and appropriate constellation of services. In addition to availability of contraceptives, availability of other materials and trained provider were assessed as these resources are crucial to provide quality service [16].

Different data sources and data collection methods (client exit interview, observation and provider interview) were used. Data collection tools were adapted from standard tools $[17,18]$, translated to local language (Afan oromo for exit interview and Amharic for provider interview) and pre-tested.
We interviewed clients of FP service over one month study period. Exit interviews were completed by unemployed nurses who had diploma and speak local language. Observation of counselling session of new clients or clients continuing after discontinuation were done by nurses and health officers who had bachelor degree and working in other health center. Semi-structured questionnaire was self-administered to interview providers who had more than six months experience. To get more about data sources and items measured, see additional file (Additional file 1).

Evaluation is most effective, meaningful and useful when it is conducted with stakeholders using participatory and learning-oriented approaches. Involving stakeholders in evaluation processes contributes to building their own capacity to do future evaluation work [19, 20]. For this reason, program evaluation indicators and measurement matrix were prepared as operational definition in agreement with program stakeholders and are available in additional file (Additional file 1). Even though stakeholders of family planning program are diverse, we included program implementers (program officers and service providers) to develop performance measurement matrix. The overall findings were summarized and compared with preset performance judgment criteria to judge the level of achievement (Table 1 and Additional file 1).

Data were entered in to Epi-data entry version 3.1 and exported to SPSS for windows version 16 for data analysis. Descriptive statistical tests were used to describe study variables. Qualitative data were analyzed manually by coding, categorizing, and thematising.

Ethical clearance was obtained from Jimma University College of Public Health and Medical Science Ethical Committee. Verbal consent was obtained from all respondents (both provider and client for observation) after through explanation of study objective. Data were analyzed anonymously and confidentiality was guaranteed.

\section{Results}

A total of 181 clients were interviewed (103 from Nada and 78 from Asendabo $\mathrm{HC}$ ) over one month. Half of clients (50.3\%) were unable to read and write and about

Table 1 Overall judgment matrix for evaluating the level of implementation, Omo Nada district, 2011

\begin{tabular}{ll}
\hline Performance criteria & Performance level \\
\hline$\leq 25 \%$ & No implementation \\
$26-50 \%$ & Critical \\
$51-65 \%$ & Acceptable \\
$66-80 \%$ & Good \\
$81-90 \%$ & Very good \\
$91-100 \%$ & Excellent \\
\hline
\end{tabular}


two fifths (38.7\%) were in age range of 15-20 (with mean of 23.99 and $\mathrm{SD}=5.26$ ). Majority of clients (91.2\%) were married and $76.2 \%$ had $1-4$ living children (Table 2).
A total of 30 client-provider interaction sessions (15 from each $\mathrm{HC}$ ) were observed from which 25 sessions were counseling of new clients while 5 were counseling of clients continuing after discontinuation. Majority, 28

Table 2 Socio-demographic characteristics of clients using FP program in Omo Nada district, 2011

\begin{tabular}{|c|c|c|c|}
\hline Socio-demographic characteristics & & $\begin{array}{l}\text { Frequency } \\
(n=181)\end{array}$ & Percent \\
\hline \multirow[t]{5}{*}{ Age } & $15-20$ & 70 & 38.7 \\
\hline & $21-25$ & 50 & 27.6 \\
\hline & $26-30$ & 45 & 24.9 \\
\hline & $31-35$ & 13 & 7.2 \\
\hline & $>35$ & 3 & 1.6 \\
\hline \multirow[t]{5}{*}{ Educational background } & Can't read and write & 91 & 50.3 \\
\hline & $1-4$ & 18 & 9.9 \\
\hline & $5-8$ & 39 & 21.5 \\
\hline & $9-10$ & 20 & 11.1 \\
\hline & $>10$ & 13 & 7.2 \\
\hline \multirow[t]{5}{*}{ Ethnicity } & Oromo & 146 & 80.7 \\
\hline & Amhara & 19 & 10.5 \\
\hline & Yem & 13 & 7.2 \\
\hline & Hadiya & 2 & 1.1 \\
\hline & Other & 1 & 0.5 \\
\hline \multirow[t]{3}{*}{ Religion } & Muslim & 125 & 69.1 \\
\hline & Orthodox & 49 & 27.1 \\
\hline & Protestant & 7 & 3.8 \\
\hline \multirow[t]{5}{*}{ Occupation } & Farmer & 99 & 54.7 \\
\hline & Merchant & 49 & 27.1 \\
\hline & Student & 14 & 7.7 \\
\hline & Employed & 17 & 9.4 \\
\hline & Other & 2 & 1.1 \\
\hline \multirow[t]{4}{*}{ Marital status } & Married & 165 & 91.2 \\
\hline & Single & 12 & 6.6 \\
\hline & Divorced & 3 & 1.7 \\
\hline & Widowed & 1 & 0.5 \\
\hline \multirow[t]{5}{*}{ Monthly income } & $<250$ & 89 & 49.2 \\
\hline & $251-500$ & 58 & 32.0 \\
\hline & $501-750$ & 19 & 10.5 \\
\hline & $751-1000$ & 14 & 7.7 \\
\hline & $>1000$ & 1 & 0.6 \\
\hline \multirow[t]{3}{*}{ Desire to have number of children } & Not decided & 48 & 26.5 \\
\hline & $1-4$ & 53 & 29.3 \\
\hline & $>4$ & 80 & 44.2 \\
\hline \multirow[t]{3}{*}{ Living children } & No children & 24 & 13.3 \\
\hline & $1-4$ & 138 & 76.2 \\
\hline & $>4$ & 19 & 10.5 \\
\hline Total & & 181 & 100 \\
\hline
\end{tabular}


(93.3\%), of sessions were provided by female providers. Most sessions, 22 (73.3\%), were provided by clinical nurses and rest $8(26.7 \%)$ by mid-wife nurses.

Majority of providers (8 out of 10) interviewed were clinical nurses and all were diploma holders. Mean age of providers was 27.5 years $(\mathrm{SD}=7.35)$ (Table 3$)$.

\section{Availability}

We assessed availability of 6 choices of contraceptives (pills, Depo-Provera, implant, condom, emergency contraceptive and natural method counselling), trained provider, 13 amenities and materials (running water, waiting room, toilet, private room, hand washing water, soap, gloves, sharp box, height-weight scale, examination table, disinfectant, speculum and BP apparatus) and 5 IEC materials and guidelines (posters, sample contraceptives, flip charts, clinical guidelines and any other guidelines). Four contraceptive options, trained provider, 9 amenities and materials and 2 IEC materials were seen. This yielded $64 \%$ for measuring availability of materials for service provision (Additional file 1).

\section{Information provided}

During observation, majority of clients, 28 (93.3\%), were informed about available methods, decided and received method of their choice. The same proportion (93.3\%) of clients were informed about injectable while emergency

Table 3 Socio-demographic characteristics of providers working in HCs in Omo Nada district, 2011

\begin{tabular}{llcc}
\hline Characteristics & & Frequency & Percent \\
\hline Sex & Male & 6 & 60 \\
Age & Female & 4 & 40 \\
& $20-30$ & 8 & 80 \\
& $31-40$ & 1 & 10 \\
Educational background & $>40$ & 1 & 10 \\
Ethnicity & Diploma & 10 & 100 \\
& Oromo & 7 & 70 \\
Religion & Amhara & 1 & 10 \\
\multirow{2}{*}{ Marital status } & Other & 2 & 20 \\
\multirow{2}{*}{ Profession } & Muslim & 4 & 40 \\
& Orthodox & 6 & 60 \\
Work experience (year) & Married & 7 & 70 \\
& Single & 3 & 30 \\
& Clinical Nurse & 8 & 80 \\
& Mid-wife & 2 & 20 \\
& $0.5-2$ & 5 & 50 \\
& $2.1-10$ & 3 & 30 \\
& $>10$ & 2 & 20 \\
& Total & 10 & 100 \\
\hline
\end{tabular}

contraceptive and natural method counseling were not discussed in both HCs (Fig. 1).

\section{Choice of method}

From 181 respondents, 179 (98.9\%) received contraceptives while 2 clients received only counselling on reproductive health. Majority of clients, 177(97.8\%), used contraceptives of their choice, most preferred Depo-Provera (Fig. 2).

Basic information that should be provided for clients in relation to chosen method were assessed using client exit interview and observation. Except advantages and how to use, all other information provided was higher with observation but both data collection methods showed that information regarding HIV prevention was missed (0\%) (Fig. 3).

\section{Interpersonal relation}

To measure interpersonal relation, clients feeling about expressing ideas freely and privacy during counselling and examination were assessed. About two thirds, 116 (64.1\%), of clients said that they expressed their ideas freely while $30(16.6 \%)$ complained that privacy was not maintained.

\section{Technical competence}

During observation, thirty five activities and counselling (from welcoming to giving appointment) were assessed. The assessment showed that some of key activities/ counselling like checking weight, height and assessing history of STI/s were not done for all observed cases while blood pressure was measured only for $2(6.7 \%)$ cases. All clients were encouraged to continue using FP by discussing return visit and giving appointment. Overall measurement of technical competence gave 167.1/ 350 (Table 4).

\section{Mechanism to encourage continuity}

To assess mechanism to encourage continuity, client-based mechanism of follow-up was assessed. Client-based mechanism of follow-up assessed were providing appointment card and information when to return. The assessment showed that all clients had follow-up appointment card and were told where to go for resupply. But exit interview showed that information on what to do if problem arise was given only to 19 (10.5\%) clients.

\section{Constellation of service}

According to Bruce, constellation of service is the way how service is organized and convenient to the clients. It is least universal and most conditioned by context [15]. In this case, we considered satisfaction, service integration, accessibility and average client waiting time. 


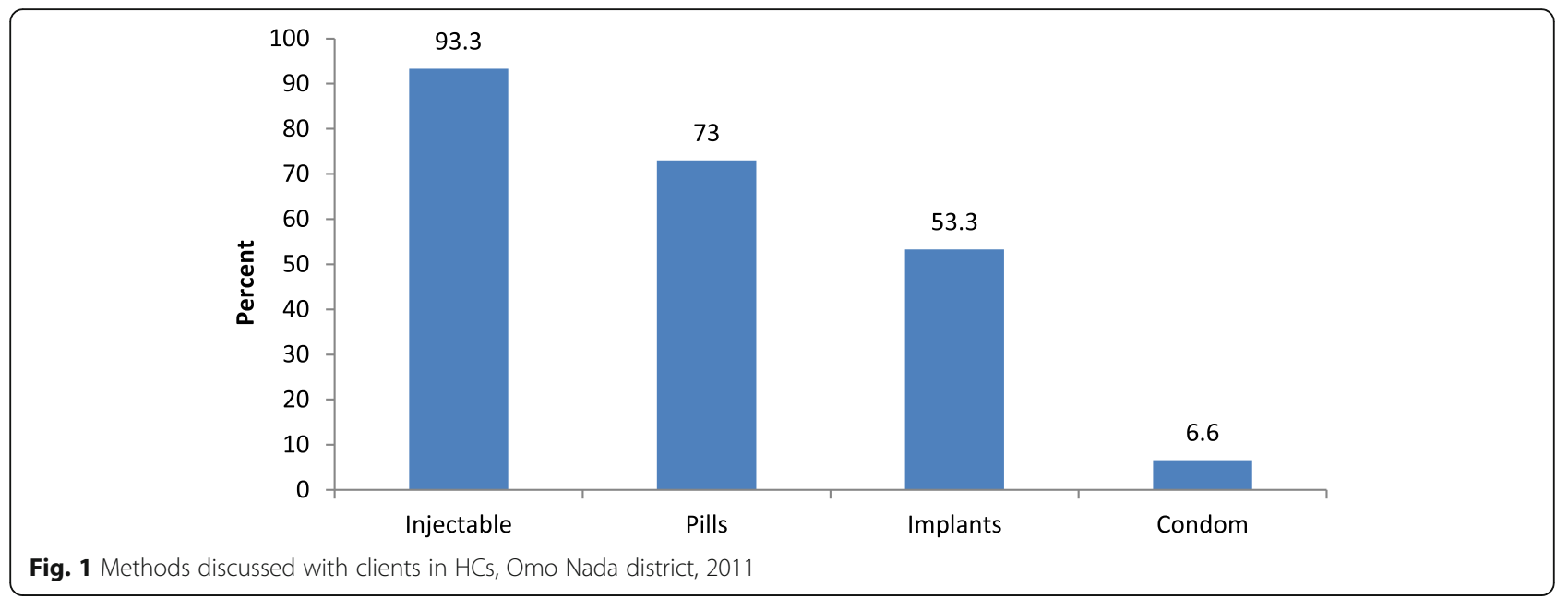

\section{Satisfaction}

More than half of clients, 107 (59.1\%), were very satisfied and $70(38.7 \%)$ were satisfied with the service they were using while only $2(1.1 \%)$ were dissatisfied and the same number of clients $2(1.1 \%)$ were very dissatisfied with the service and mentioned waiting time as cause of their dissatisfaction.

Eight $(80 \%)$ providers were satisfied with service they were providing but $2(20 \%)$ were not satisfied. The cause of dissatisfaction for one provider was management while other provider associated dissatisfaction with poor performance saying:

"Since I'm serving community, my satisfaction is when community awareness is changed and improved; but little is done within community, so I'm dissatisfied".

(Male, clinical nurse, 10 years' experience)

\section{Service integration}

About one-fourth of clients, 47(26\%), used integrated services from which one client received TT vaccination and 46 clients were tested for HIV. But from 181 clients, $142(78.5 \%)$ said that they received TT vaccination in past and $154(85.1 \%)$ reported that they were tested for HIV/AIDS.

Integration of FP service with OPD, STI treatment, VCT, safe abortion, EPI, post abortion care and PNC were assessed by providers' interview. Three services (PNC, EPI and post abortion care) were reported as integrated by more than half of providers.

\section{Geographical accessibility}

About three fourths (77.4\%) of clients reported that they had walked less than $1 \mathrm{~h}$ to reach $\mathrm{HC}$ while 14.4, 7.7 and $0.5 \%$ said that they had walked $1-2 \mathrm{~h} / \mathrm{s}, 2-3 \mathrm{~h}$ and

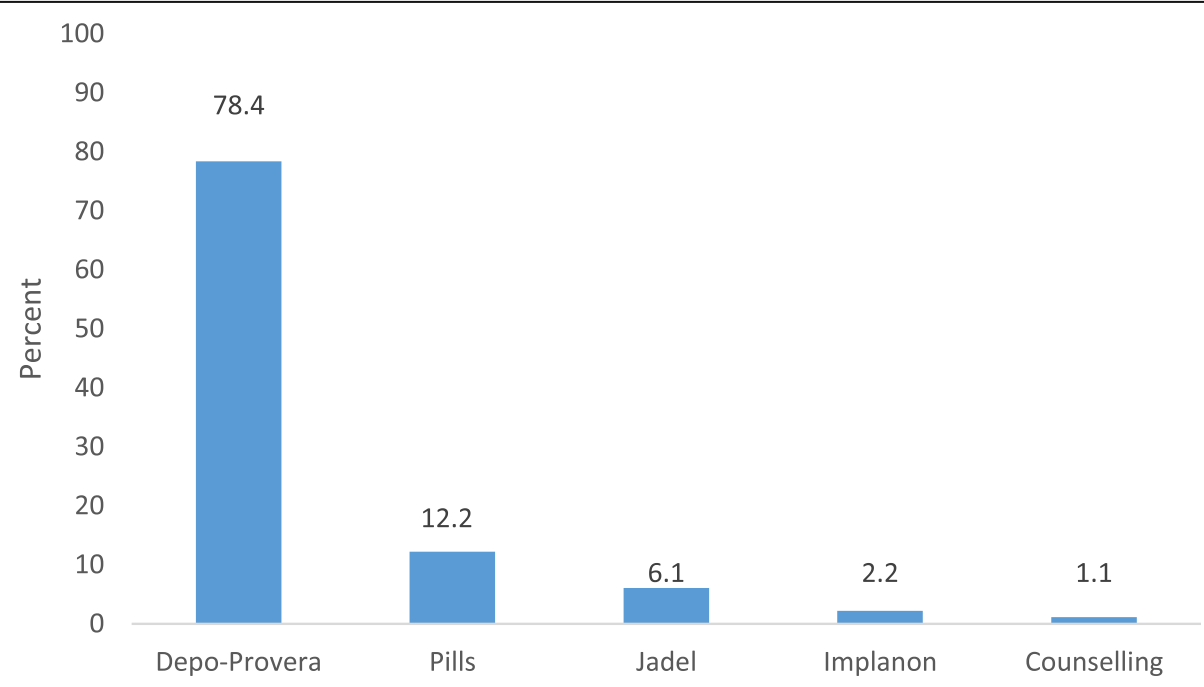

Fig. 2 Contraceptives methods used by clients in HCs, Omo Nada district, 2011 


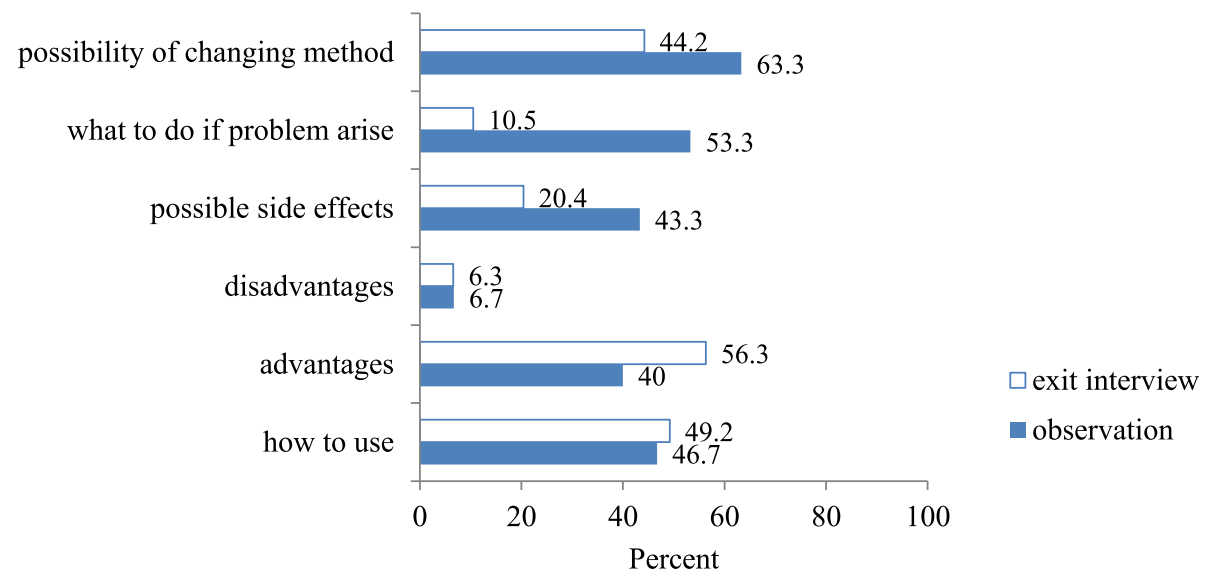

Fig. 3 Comparison of information provided with observation and exit interview, Omo Nada district, 2011

more than $3 \mathrm{~h}$ respectively. Mean walking time was $51.5 \min (\mathrm{SD}=47.78)$.

\section{Waiting time}

The average waiting time was $10.38 \mathrm{~min}(\mathrm{SD}=4.8)$. About three fifths, 115(63.5\%), of clients waited less than ten minutes while the rest $66(36.5 \%)$ waited for $10-$ 20-min to see provider.

\section{Overall judgment}

As it was presented in above section, availability dimension was found $64 \%$ while compliance was $67 \%$. The overall program implementation level was $66.6 \%$ and was found good as per agreed criteria (Additional file 1 and Table 1).

\section{Discussion}

This process evaluation assessed program readiness and program process quality. We measured program performance as per stakeholders agreed criteria. The measurement shows that the program seems "good" as per agreed judgment matrix but notable gaps were presented as per quality of care.

Both health centers had working toilet, electricity, waiting room, and pipe water. But some of basic materials for service provision were lacking in both HCs. To mention few examination table, examination light, disinfectant solution and BP-apparatus were lacking in Asendabo $\mathrm{HC}$ while hand washing water, examination light and weight-height scale were lacking in Nada HC. These materials are very crucial for screening (assessing eligibility criteria) for contraceptive methods, following aseptic procedures and assessing for any medical conditions. The unavailability of these materials can affect clinical quality of care as presented under compliance.

Majority of clients (78.4\%) used injectable method, followed by pills (12.2\%). Even though there was slight change over time, method preference was similar with previous studies conducted in study zone [21], study region [22] and other region in the country [23]. Better progress was seen in terms of informed choice as previous study done in the study zone [21] showed that $21.1 \%$ of clients used methods that were not their choice while only $2.2 \%$ clients used methods that were not their choice in this case; this might be due to investments done in improving program and increasing community awareness.

Choice of contraceptive methods is a key element of high quality services that benefits both clients and programs. Clients benefit because they are able to select the method that best meets their needs and can switch to a different method as their needs change or if they experience difficulties which is influenced by personal concerns, health considerations, cost, and the cultural environment. Programs benefit as clients are more likely to be satisfied and continue using a method [24]. Unless providers discuss methods to users, clients might not choose methods that are not common or that they do not know. During observation, majority of clients (93.3\%) were informed about injectable while only about half (53.3\%) heard about implants. With client exit interview, only less than half of clients (44.2\%) reported that possibility of changing method was discussed. In case when problem arises, these clients might stop using contraceptive without trying another contraceptives.

Basic information that should be provided for family planning service users in relation to chosen methods was assessed using client-exit interview and observation and there were some differences between results of two data collection methods (Fig. 3). These results again differed from $\mathrm{HC}$ to $\mathrm{HC}$ except HIV/ AIDS prevention which was zero for both $\mathrm{HCs}$ with two data collection techniques. Data collected from 
Table 4 Technical competence during FP counselling in HCs, Omo Nada district, 2011

\begin{tabular}{|c|c|c|}
\hline Activities & Percent $(n=30)$ & Result out of 10 \\
\hline 1. Greet client in a friendly manner & $24(80 \%)$ & 8.0 \\
\hline 2. Encourage client to ask questions & $22(73.3 \%)$ & 7.3 \\
\hline 3. Treat client with respect & 28(93.3\%) & 9.3 \\
\hline 4. See client in private & $22(73.3 \%)$ & 7.3 \\
\hline 5. Use visual aids & $9(30 \%)$ & 3.0 \\
\hline 6. Use client's records & $30(100 \%)$ & 10 \\
\hline 7. Explicitly mention that the condom protects against STIs/HIV/AIDS & $4(13.3 \%)$ & 1.3 \\
\hline 8. Previous contact with provider & $24(80 \%)$ & 8.0 \\
\hline 9. Current age & $24(80 \%)$ & 8.0 \\
\hline 10. Marital status & 26(86.7\%) & 8.7 \\
\hline 11. Whether sexually active or abstinent & $9(30 \%)$ & 3.0 \\
\hline 12. Whether partner had more than one sexual partner in last year & $0(0 \%)$ & 0.0 \\
\hline 13. Date of last delivery & $8(26.7 \%)$ & 2.7 \\
\hline 14. Breast feeding status & $17(56.7 \%)$ & 5.7 \\
\hline 15. Regularity of menstrual cycle & $18(60 \%)$ & 6.0 \\
\hline 16. Abortion history & $6(20 \%)$ & 2.0 \\
\hline 17. Current pregnancy status & $21(70 \%)$ & 7.0 \\
\hline 18. Living children & $12(40 \%)$ & 4.0 \\
\hline 19. Desire to have more child & $5(16.7 \%)$ & 1.7 \\
\hline 20. History of contraceptive use & 26(86.7\%) & 8.7 \\
\hline 21. Current method use & $20(66.7 \%)$ & 6.7 \\
\hline 22. History of pregnancy complications & $8(26.7 \%)$ & 2.7 \\
\hline 23. Smoking status & $0(0 \%)$ & 0.0 \\
\hline 24. History of STIS & $0(0 \%)$ & 0.0 \\
\hline 25. Whether discussed contraceptives with partner(s) & $11(36.7 \%)$ & 3.7 \\
\hline 26. Ease of returning to facility & $30(100 \%)$ & 10 \\
\hline 27. Take blood pressure & $2(6.7 \%)$ & 0.7 \\
\hline 28. Check weight & $0(0 \%)$ & 0.0 \\
\hline 29. Check height & $0(0 \%)$ & 0.0 \\
\hline 30. Explain the procedure to the client & $16(53.3 \%)$ & 5.3 \\
\hline 31. Wash his or her hands before the exam & $3(10 \%)$ & 1.0 \\
\hline 32. Wash his or her hands after the exam & $3(10 \%)$ & 1.0 \\
\hline 33. Wear sterile gloves during the exam & $13(43.3 \%)$ & 4.3 \\
\hline 34. Discuss return visit & $30(100 \%)$ & 10 \\
\hline 35. Give appointment card & $30(100 \%)$ & 10 \\
\hline Total & & $167.1 / 350$ \\
\hline
\end{tabular}

exit interview showed higher figure of information on how to use and advantages than observation and these might be due to clients' past knowledge report because majority of service users were continuing users and they know at least how to use and advantages. But disadvantages, possible side effects, what to do if problem arise and possibility of changing method were higher with observation which might be due to providers' behavioral change of performance during observation as different studies reported that side effects and disadvantages are not discussed during routine service provisions $[21,22]$.

Under technical competency, assessment of clinical techniques that should be performed showed poor performance needing improvement measures. Some of critical performances included measuring height and weight $(0 \%)$, asking history of STI $(0 \%)$, asking history of smoking (0\%), measuring blood pressure (6.7\%) 
and counselling desire to have more children (16.7\%). This was much lower than reports of studies done in similar zone [21] and in other region [25]. During assessment of availability of materials for quality service provision, it was noted that there was shortage of BP apparatus and though there were trained providers, most sessions were provided by untrained providers. While majority of clients missed important services, they were satisfied with the service which could be influenced by their awareness of clinical standard and rural context as satisfaction is more contextual than universal.

The mechanism to encourage continuity of service includes mass media and client-based tools, but here only client-based mechanism especially client follow-up (client card and information provided when to return) was assessed. The assessment with both observation and exit interview showed that in both HCs, all clients had follow-up card and with observation, all clients were told where to go for resupply. Counseling what to do if problem arise is good way to encourage clients but only 19 (10.5\%) clients heard what to do if problem arise.

Government of Ethiopia is doing much to make FP accessible through health extension program by which health extension workers are assigned in health posts at Kebele level (smallest administrative structure). As result, majority of clients (77.3\%) traveled less an hour to get service. In addition, the average waiting time was also 10.38 min though it was cause for dissatisfaction of some clients $(2.2 \%)$.

\section{Conclusion}

Although clients were satisfied and program implementation level was good according to stakeholders agreed judgments, several deficiencies like unavailability of crucial materials, poor technical performance including poor information provision, poor integration of services, and failure to follow infection prevention procedures were noted. Crucial materials for provision of quality service should be availed and providers should strictly adhere to clinical guidelines. Quality of process should be monitored to improve service by integrating existing services in resource limited setting.

\section{Additional file}

Additional file 1: Evaluation dimension, indicators and source of data for evaluation of FP program, Omo Nada district, 2011. (DOCX $17 \mathrm{~kb}$ )

\section{Abbreviations}

AIDS: Acquired Immune Deficiency Syndrome; EPI: Expanded Program on Immunization; FP: Family planning; HC: Health Center; HIV: human immunodeficiency virus; IEC: Information, Education and Communication;
IUCD: Intrauterine Contraceptive Device; OPD: Out Patient Department; PNC: Postnatal Care; RH: Reproductive Health; SPSS: Statistical Package for the Social Sciences; STI: Sexually Transmitted Infections; TT: Tetanus Toxoid; VCT: Voluntary Counselling and Testing

\section{Funding}

This study was supported by Jimma University. The funder had no role in study design, data collection and analysis, decision to publish, or preparation of the manuscript

\section{Availability of data and materials}

All relevant data are within the manuscript. The datasets analysed during the current study available from the corresponding author on reasonable request.

\section{Authors' contributions}

All authors participated in proposal development, data analysis, report and manuscript writing. All authors read and approved the final manuscript.

\section{Ethics approval and consent to participate}

Ethical clearance was obtained from Ethical Review Committee of Jimma University College of public health and medical science ethical committee.

Consent for publication

Not applicable, no individual detail is presented.

\section{Competing interests}

All authors have no competing interest and declare that this study is original article.

\section{Publisher's Note}

Springer Nature remains neutral with regard to jurisdictional claims in published maps and institutional affiliations.

\section{Author details}

${ }^{1}$ Health Research and Technology Transfer Support Process, SNNPR Health Bureau, Hawassa, Ethiopia. ${ }^{2}$ Department of Population and Family Health, Jimma University, Jimma, Ethiopia. ${ }^{3}$ Department of Health Economics, Management and Policy, Jimma University, Jimma, Ethiopia.

Received: 6 November 2017 Accepted: 20 June 2018

Published online: 01 August 2018

References

1. Smith R, Ashford L, Gribble J, Clifton D. Family planning saves lives. In: Population reference bureau; 2009.

2. Ministry of Health [Ethiopia]. National Guideline for family planning Services in Ethiopia. Addis Ababa: Ministry of Health [Ethiopia]; 2011.

3. Costs and Benefits of Investing in Contraceptive Services in the Developing World. New York: UNFPA and Guttmacher Institute; 2012.

4. Ibañez XA, Melo LA, Ibañez XA, Fine J, Shoranick T, Toure A, et al. The right to contraceptive information and services for women and adolescents. New York: Center for Reproductive Rights and United Nations Population Fund; 2010.

5. Singh S, Darroch JE, Ashford LS, Vlassoff M. Adding It Up: The Costs and Benefits of Investing in Family Planning and Maternal and Newborn Health. New York: Guttmacher Institute and UNFPA; 2009.

6. Glasier A, Gülmezoglu AM, Schmid GP, Moreno CG, Van Look PFA. Sexual and reproductive health: a matter of life and death. The Lancet. 2006; 368(9547):1595-607.

7. Sundaram A, Vlassoff BA, Remez L, Gebrehiwot $Y$. Benefits of meeting the contraceptive needs of Ethiopian women. In: Brief: New York: Guttmacher Institute; 2010. No. 1.

8. FMOH. Health Sector Development Program IV 2010/11-2014/15. Ethiopia: Federal Minstry of Health; 2010.

9. Central Statistical Agency [Ethiopia] and ICF International. Ethiopia Demographic and Health Survey 2011. Addis Ababa, Ethiopia and Calverton, Maryland, USA: Central Statistical Agency [Ethiopia] and ICF International; 2012.

10. Lerberghe W, Manuel A, Matthews Z, Wolfheim C, Phumaphi J, Evans T, et al. The world health report 2005: make every mother and child count Geneva: World Health Organization; 2005. 
11. Ministry of Public Health and Sanitation [Kenya]. National Family Planning Guidelines for service providers National Family Planning Guidelines for service providers: updated to reflect the 2009 medical eligibility criteria of the World Health Organization. Nairobi: Division of Reproductive Health; 2010.

12. Yin RK. Case study research design and methods. 3rd ed. California: Sage Publications; 2003.

13. Worthen BR, Sanders JR, Fitzpatrick JL. Program evaluation: alternative approaches and practical guidelines. Boston: Allyn and Bacon; 2003.

14. Donabedian A. The seven pillars of quality. Arch Pathol Lab Med. 1990; 114(11):1115-8.

15. Bruce J. Fundamental elements of the quality of care: a simple framework. Stud Fam Plan. 1990;21(2):61-91.

16. Penchansky R. The concept of access: definition and relationship to consumer satisfaction. Med Care. 1981:19(2):127-40.

17. Pathfinder International. A guide to monitoring and evaluating adolescent reproductive health programs: instruments and questionnaires, part two. 2000.

18. MEASURE Evaluation Project. Quick investigation of quality (QIQ): a user's guide for monitoring quality of care in family planning. New York: 2001.

19. Centers for Disease Control and Prevention. Framework for program evaluation in public health. MMWR. 1999;48(RR-11)

20. Patton MQ. Utilization focused evaluation. 3rd ed. California: SAGE publications; 1997.

21. Loha E, Asefa Z, Jira C, Tessema F. Assessment of quality of care in family planning services in Jimma zone, Southwest Ethiopia. EthiopJHealth Dev. 2003;18(1):8-18.

22. Mitike G, Tsui A, Seifu A, Hailemariam D, Betre M, Melkamu Y, et al. Quality of Family Planning Service in the Health Facilities of East Shoa Zone. Oromia Regional State, Ethiopia: Family Planning Conference; 2009.

23. Fantahun M. Quality of family planning services in Northwest Ethiopia. EthiopJHealth Dev. 2005;19(3):195-202.

24. WHO. Health benefits of family planning. Geneva: Unit family planning and population, division of reproductive health, WHO; 1995.

25. Tseganeh W. Assessment of Quality Of Family Planning Service, Bahar-Dar Special Zone, Amhara Regional State. Addis Ababa: Addis Ababa University; 2005.

\section{Ready to submit your research? Choose BMC and benefit from:}

- fast, convenient online submission

- thorough peer review by experienced researchers in your field

- rapid publication on acceptance

- support for research data, including large and complex data types

- gold Open Access which fosters wider collaboration and increased citations

- maximum visibility for your research: over $100 \mathrm{M}$ website views per year

At BMC, research is always in progress.

Learn more biomedcentral.com/submissions 